\title{
Dynamic scenario of metabolic pathway adaptation in tumors and therapeutic approach
}

\author{
Silvia Peppicelli ${ }^{1}$, Francesca Bianchini ${ }^{1}$ and Lido Calorini ${ }^{1}$ \\ ${ }^{1}$ Department of Experimental and Clinical Biomedical Sciences, University of Florence, Istituto Toscano Tumori \\ Correspondence to: Lido Calorini, email: lido.calorini@unifi.it \\ Keywords: "Warburg effect", hypoxia-inducible factor-1a, oxidative phosphorylation, proliferation, migration, metabolic-target \\ therapy \\ Received: November 19, $2014 \quad$ Accepted: Febraury 06, $2015 \quad$ Published: Febraury 09, 2015
}

This is an open-access article distributed under the terms of the Creative Commons Attribution License, which permits unrestricted use, distribution, and reproduction in any medium, provided the original author and source are credited.

\section{ABSTRACT}

Cancer cells need to regulate their metabolic program to fuel several activities, including unlimited proliferation, resistance to cell death, invasion and metastasis. The aim of this work is to revise this complex scenario. Starting from proliferating cancer cells located in well-oxygenated regions, they may express the so-called "Warburg effect" or aerobic glycolysis, meaning that although a plenty of oxygen is available, cancer cells choose glycolysis, the sole pathway that allows a biomass formation and DNA duplication, needed for cell division. Although oxygen does not represent the primary font of energy, diffusion rate reduces oxygen tension and the emerging hypoxia promotes "anaerobic glycolysis" through the hypoxia inducible factor-1a-dependent up-regulation. The acquired hypoxic phenotype is endowed with high resistance to cell death and high migration capacities, although these cells are less proliferating. Cells using aerobic or anaerobic glycolysis survive only in case they extrude acidic metabolites acidifying the extracellular space. Acidosis drives cancer cells from glycolysis to OxPhos, and OxPhos transforms the available alternative substrates into energy used to fuel migration and distant organ colonization.

Thus, metabolic adaptations sustain different energy-requiring ability of cancer cells, but render them responsive to perturbations by anti-metabolic agents, such as inhibitors of glycolysis and/or OxPhos.

\section{INTRODUCTION}

In genetic unstable tumor cells, environmental restrictions may stimulate a rapid emergence of a new panel of different subpopulations that may reach stable proportions until the next selection pressure(s) is encountered. Hence, primary tumors are heterogeneous and contain subpopulations of cells that differ in several abilities, such as sustained proliferative signaling, resistance to cell death, invasion and metastatic dissemination [1]. Proliferation, in particular, occurs irrespective of external stimuli, as genetic and epigenetic alterations favor autocrine growth signaling and pathways supporting nutrient uptake and use. Cancer cell proliferation relays on availability of necessary substrates provided by an adequate blood supply, and, necessarily, space as the two major limiting factors. As the cells accumulate and periods of possible environmental stress may alter rate of proliferation and viability, an additional strategy to survive has to adapt. Thereafter, cancer cells migrate into surrounding tissues following destruction and dissolution of collagen and non-collagenous glycoproteins of extracellular matrix, properties related with high motility and secretion of proteolytic enzymes. Thus, cancer cells have to adjust their energy metabolism to fuel different tasks in which are involved [2-4].

Cancer metabolism is now a hot hallmark in cancer, which needs to be revised in order to clarify causes and consequences $[4,5]$. The currently renaissance of cancer metabolism also derives from the observation that many oncogenic signals driving tumorigenesis are key regulators of metabolic network [6, 7]. A classical representation of experimental tumors identifies a well oxygenated tumor cell subpopulation located in the vicinity to blood vessels using lactate to fuel oxidative metabolism and sparing glucose, and a distant hypoxic cells using glucose and 
producing lactate for a metabolic symbiosis model [8] Herein, we intend to revise and offer an integrated model of metabolic adaptation of cancer cells from proliferation to invasion. This view offers the possibility to disclose new strategies based on the anti-metabolic supporting therapy of tumors.

\section{Metabolic scenario in tumors (see Fig. 1)}

Cancer cells undergoing proliferation have to stimulate biomass formation and replicate their genome before to divide into two daughter cells, for that reason the metabolic program of proliferating cancer cells has to satisfy the anabolic demands of macromolecular biosynthesis. Starting from glucose, the glycolytic flux allows generation ATP and biosynthetic precursors of several macromolecules, including those generating lipids, proteins and nucleic acids, necessary to proliferate. This is done via: a) the pentose phosphate pathway and involves the nicotinamtide adenine dinucleotide phosphate (NADPH) generation, used for ribose-5-phosphate and fatty acid synthesis; b) 3-phosphoglycerate (3-PG), which may be used for amino acid and lipid synthesis; and c) the fraction of pyruvate not converted into lactate which furnishes an additional substrate for amino acid synthesis (serine, glycine) and, whether transferred into the tricarboxylic acid (TCA) cycle, generates citrate for lipid biosynthesis and protein acetylation [2, 3, 9]. Therefore, mitochondria participate actively in sustaining biosynthetic pathways in proliferating cancer cells, and an improved uptake of glutamine and glutaminolysis reconstitute TCA intermediates to prevent loss of mitochondrial integrity [10-11].

Overall, a special, but "not" unexpected, characteristic of proliferating cancer cells is a persistence in using specially glycolysis, even in presence of a tension of oxygen able to support oxidative phosphorylation (OxPhos), the so-called "aerobic glycolysis" or "Warburg effect" $[9,12,13]$. It is reasonable whether carbon molecules were entirely oxidized to $\mathrm{CO}_{2}$ in mitochondria, biomass generation from glucose results impossible. Elevated glycolysis in cancer cells represents a likely constitutive phenomenon, independent from oxygen tension. Indeed, c-Myc deregulation is able to promote expression of glucose transporters and glycolytic enzymes [14-16]. The serine threonine kinase Akt is also known as the main inducer of the glucose-lactate pathway, inducing glucose transporter, glycolytic enzymes and phosphorylation and activation of citrate lyase working to increase lipid synthesis $[17,18]$. Phosphatidylinositol-

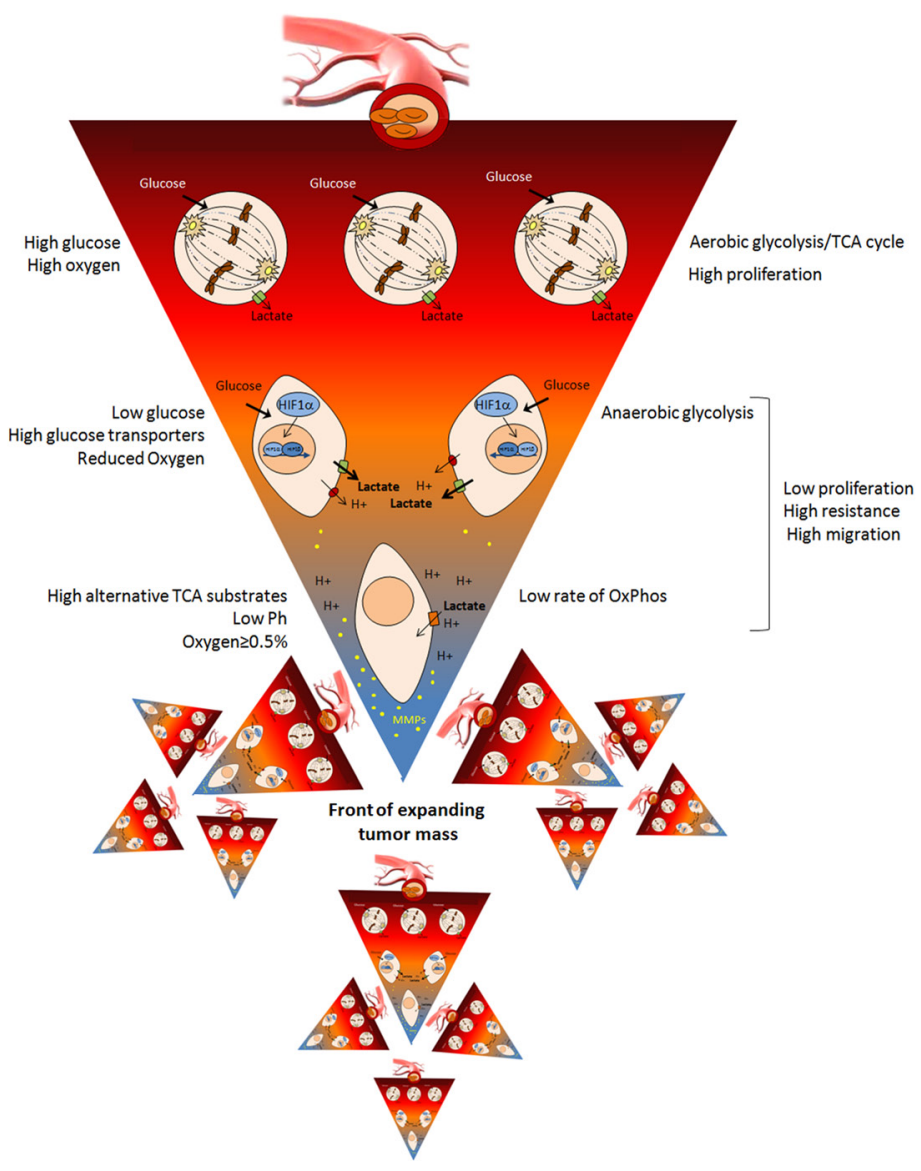

Fig.1: "Inverse pyramid" of metabolic adaptations of tumor cells. 
3-OH kinase (PI3K), Akt and mammalian target of rapamycin (mTOR) pathway elicit both expression of amino acid transporters and protein translation, thereby coordinating protein synthesis; PTEN acts as a regulator of this flux of information $[3,4,9]$. Furthermore, cancer cells of several tumor histotype express high level and activity of pyruvate kinase (PK) M2 type (PKM2) produced by alternative splicing of the $P K M$ gene, which catalyzes the rate-limiting step of glycolysis, controlling conversion of phosphoenolpyruvate (PEP) to pyruvate, and thus ATP generation $[6,19]$. By slowing the passage of metabolites through glycolysis, PKM2 promotes the accumulation of large quantities of NADPH and other macromolecules needed to support cell division. PKM2 isoform expression is controlled by c-Myc [14]. Thus, a well-coordinated molecular events may sustain "Warburg effect".

Glycolysis, although energetically inefficient, relative to mitochondrial OxPhos, can satisfy the energetic yield and pyruvate for TCA cycle of proliferating cancer cells through a more rapid flux and an intense uptake of glucose. It is generally accepted that during tumor progression an inflammatory response operates locally promoting systemic changes, among which a sustained decline in insulin sensitivity would allow the redistribution of glucose from major consumers (e.g. skeletal muscle) to tumor cells. In fact, bioenergetic measurements demonstrate that ATP concentrations in tumors is only slightly modified in respect to normal tissues, and an inefficient ATP generation rises only when substrates are limited $[20,21]$. The $\left[{ }^{18} \mathrm{~F}\right]$ fluoro-2-deoxyglucose (FDG) positron emission tomography $\left({ }^{18} \mathrm{~F}-\mathrm{PET}\right)$ imaging of tumors reveals glucose uptake by cancer cells. FDG is taken up by glucose transporters and phosphorylated by hexokinase enabling tumor tissue visualization [22]. Besides, imaging technique indicate that around 30\% of tumors are not ${ }^{18} \mathrm{~F}$-PET-positive, demonstrating that metabolic profile of tumors is not always glycolytic, and new metabolic tracers are necessary [23].

Although, proliferating cancer cells, which usually located near the vascular tree, use more glucose than oxygen, oxygenation level can be worsened increasing diffusion distance in the tissues. Thus, low oxygen tension areas develop promoting a less proliferating, but more resistant tumor cell phenotype. A key regulator of cellular response to hypoxia is the hypoxia-inducible factor-1 (HIF-1) transcription factor complex, progressively activated in cancer cells by low oxygen tension (mild of 7-21 to severe hypoxia of $1.4-0.7 \mathrm{mmHg}$ ) [24]. HIF1 activity requires the subunit HIF-1 $\alpha$, which works as a master-transcriptional activator for a group of genes involved in cell survival, angiogenesis, migration, energy metabolism and $\mathrm{pH}$ regulation $[25,26]$. HIF-1 $\alpha$ increases migration of tumor cells promoting epithelialto-mesenchymal transition (EMT) [25], a mesenchymal phenotype expressing invasive and motogenic properties, crucial in local invasiveness and secondary organ colonization [27]. Cells, under HIF-1 $\alpha$ control, continue to adopt glycolysis ("anaerobic glycolysis"). HIF-1 $\alpha$ renders cancer cells more efficient in mobilizing the residual glucose strengthening glucose transporters (GLUT1 and 3 ), and stimulates gene transcription of several proteins involved in glucose metabolism, such as aldolase A, enolase-1, esokinase 1 and 3, lactate dehydrogenase A (LDH-A), phosphofructokinase-1 (PFK-1) and PKM2. HIF-1 $\alpha$, concomitantly, represses entry of pyruvate into TCA cycle, inhibiting pyruvate dehydrogenase (PDH) by pyruvate dehydrogenase kinase (PDK) activation [28]. The reduced pyruvate entry into TCA cycle reduces intermediates for biosynthesis necessary for proliferating cells. It has been found that the reduced citrate synthesis can be restored by a significant amount of lipogenic acetyl-CoA provided by glutamine, captured at higher rate by hypoxic than normoxic cells [29]. Thus, HIF-1 $\alpha$ may works as a fine-regulator of energy program and migration. HIF- $1 \alpha$ is also stabilized by PI3K/Akt/mTOR pathway activation, indicating a converging activation signaling for HIF-1 $\alpha$-dependent glycolysis stabilization [25]. Consequence of these changes is a reduced proliferation, necessary adaptation to survive in a low substratecontaining environment. In fact HIF-1 $\alpha$ promotes block of G1/S transition of cell cycle, affecting cyclindependent p21 and p27 kinases [30]. HIF-1 $\alpha$ has also been demonstrated to increase resistance of cells to apoptosis process [31] and activates Notch and Oct4 signaling that control self renewal and multipotency of stem cells [32]. A risk of anaerobic glycolysis is the increase lactic acid production, that needs to be removed from cells in order to avoid a drop in intracellular $\mathrm{pH}$, that could result in cell damage. To contrast this effect, HIF-1 $\alpha$ induces monocarboxylate transporter 4 (MCT4) and carbonic anhydrase IX activity that mediate lactic acid efflux and catalysis of reversible $\mathrm{CO}_{2}$ hydration, respectively $[26,33]$. Koukourakis and collegue. [34], report that preferential expression of MCT1, which promotes entry of lactate into the cell, and LDH-1 together with elevated PDH activity in tumor fibroblasts support the metabolic use of lactate produced by tumor cells, preventing the development of a hostile acidic environment. The Cori cycle in the liver may also promote reprocessing lactate to glucose, causing a minimum change on energy reserve of whole organism. Nevertheless, in tumors there is a $\mathrm{pH}$ gradient with intracellular greater than extracellular $\mathrm{pH}$, reverse of that found in normal tissues. Although acidity is "primarily" caused by endogenous metabolism of cancer cells choosing "Warburg effect" or anaerobic glycolysis, a chaotic vasculature, a reduced intratumoral lymphatic vessels and an altered intratumoral fluid dynamics, due to increased fluid pressure, participate to extracellular tumor acidity development, with a $\mathrm{pH}$ value even lower than 6.5 [35].

The reduced $\mathrm{pH}$ of tumor microenvironment now triggers in cancer cells, possibly through G-protein- 
coupled receptors (such as OGR1 and GPR4) [36], signals to stop dividing and gain new vascularized space in adjacent host tissues. Cancer cells with internal $\mathrm{pH}$ below 7.1 do not progress into G1/S phase even when an excess of growth factors was applied [37]. Thus, acidic melanoma cells undergo epithelial-to-mesenchymal transition (EMT) [38], just experienced in hypoxic regions, and reprogram their metabolism to a pathway more efficient in ATP production starting from residual energetic substrates. A reduced extracellular $\mathrm{pH}$ favors glycolysis inhibition by HIF-1 $\alpha$ deregulation [39], and promotes OxPhos pathway [40]. Acidosis inhibits glycolytic enzymes including phosphofructokinase activity, reduces expression of glucose transporters and allows TCA cycle recovering. Unlike cells grown at standard $\mathrm{pH}(\mathrm{pH} 7.3)$, cancer cells adapted at pH 6.7 do not exhibit "the Crabtree effect" during exposure to high glucose [41]. Low-pH adapted cells exposed to high glucose, instead of to progress toward glycolysis pathway, express a higher pyruvate oxidation [41]. Moreover, it has been demonstrated that glucose depletion leading to a declined ATP production promotes AMP-activated protein kinase (AMPK), a protein kinase complex that regulates cellular energy homeostasis, before cells undergo a state of energetic failure trigging cell death. AMPK activation promotes ATP-generating process such as fatty acid oxidation and electron transport, and inhibits ATP-consuming processes, such as protein, cholesterol and fatty acid synthesis. AMPK-dependent p53 activation negatively regulates cell cycle progression, glycolysis flux through inhibition $\mathrm{PI} 3 \mathrm{~K} / \mathrm{Akt} / \mathrm{mTOR}$ pathway, resulting in a p53-dependent metabolic shift toward OxPhos [42, 23]. It has been shown that acidosis through a p53-dependent pathway disconnects ribose synthesis from oxidative pentose phosphate pathway and stimulates glutaminolysis, in order to increase bioenergetics capacity and reactive oxygen species neutralization [43]. It is fascinating to believe that acidosis might play a role in protection of tissues from an ischemic damage. Not yet completely understood is the role played by NF-kB on tumor cell metabolism, although NF-kB is crucial for VEGF-C expression in acidic melanoma cells [44]. OxPhos, whether oxygen tension is still enough ( $\geq 3.5 \mathrm{mmHg}$ ), may work using alternative substrates, such as lactate, free fatty acids and amino acids, to satisfy the high energetic demand of high motile cancer cells. Thus, lactate produced by glycolytic cancer cells, either using Warburg effect or anaerobic glycolysis, constitutes an alternative metabolic fuel for acidic cancer cells expressing an oxidative metabolism. Tumor-associated fibroblasts have been documented to participate in lactate homeostasis in tumors. Fibroblasts in contact with epithelial cancer cells undergo myofibroblast differentiation and produce lactate through aerobic glycolysis which is used by cancer cells for respiration [45-47]. A chronic exposure to low $\mathrm{pH}$ ( $\mathrm{pH} 6.5$ medium for 8 weeks) stimulates in tumor cells of cervix, colon and pharynx tumors a mitochondrial respiration fueled by glutamine through Sirt1/HIF2 $\alpha$ axis [48].

Migration, on the other hand, is a complex process requiring a coordinated action of multiple active macromolecules, implicated in adhesiveness, cytoskeletal dynamic and digestion of extracellular matrix. It was found that melanoma cells reach a maximum of migration at $\mathrm{pH} 7.0$ [49] and acidosis promotes in cancer cells an aggressive phenotype characterized by high resistance to apoptosis, high invasiveness and metastasis, favoring lodgment into target organs [38]. Low extracellular $\mathrm{pH}$ favors activation of several proteases, such as metalloproteases (MMP), including MMP-3 and MMP9, urokinase-type plasminogen activator, cathepsin B and L [35]. MMP-3 and 9 are tightly correlated with the induction of EMT in cancer cells, the characteristic profile adopted by cancer cells to freely migrate into surrounding tissues [38]. Very recently, LeBleu and collegue. indicate that circulating cancer cells undergoing EMT characterized by a high migratory ability and metastatic dissemination, are energetically fuel by mitochondrial biogenesis and OxPhos [50].

On the whole, front of a tumor may expand although at a different rate due to various level of energy obtained from OxPhos activity or HIF-1 $\alpha$-dependent anaerobic glycolysis. Otherwise, when oxygen is not able to sustain OxPhos and environment is anoxic and acidic, cells progress irreversibly to death, justifying the frequent observation of necrosis in spontaneous tumor mass. Whether, cancer cells metastasize distant organs, possibly using OxPhos [50], either they may be dormant or, in case of adequate blood supply, they may reprogram their metabolic profile switching back to an aerobic glycolysis pathway, in order to be proliferative; a profile probably associated with a mesenchymal-to-epithelial transition program. Then, cells again may change to anaerobic glycolysis under the HIF-1 $\alpha$-dependence or acid-stimulated OxPhos to invade locally and gain new space for proliferation.

\section{Metabolic therapy}

Whether tumor metabolism might be considered "the Achilles' Heel of tumors" is yet difficult to say, however metabolic changes, directly or indirectly, accompanied any other property tumor cells acquire during progression to malignancy, such as unlimited proliferation and invasiveness.

Glycolytic inhibitors are not specific and inhibition of glycolysis does not kill tumor cells expressing a different metabolic profile. Among glycolytic inhibitors, is the non-metabolically competitive inhibitor of glucose, the 2-deoxyglucose (2-DG) which is able to suppress hexokinase II and cause a depletion of cellular ATP, leading to blockage cell cycle progression and cell death [51]. However, a dose-dependent toxicity limits 
its use in human being, although combining 2-DG with adryamicin or paclitaxel, it was found to yield an additive toxicity in human osteosarcoma and non-small cell lung cancers [52]. Other glycolytic inhibitors are: Lonidamine, an exokinase inhibitor; some arsenate compounds, that abolish ATP generation causing arsenolysis in the glyceraldehyde-3-phosphate dehydrogenase reaction; and the 3-bromopyruvate (3-BrPA), another potent inhibitor of hexokinase II, effective in killing liver cancer cells [53]. The ability of 3-BrPA to preferentially kill cancer cells with mitochondrial defects and that live in a hypoxic environment provides a biochemical basis to further develop this class of compounds as novel anticancer agents with potentially promising therapeutic activity and selectivity [54].

MCTs are overexpressed in many tumors and contribute to the maintenance of cellular alkalinity through active export (type 4) or import (type 1) of lactate, pyruvate and ketone bodies. MCT inhibitors have been shown to decrease pHi in neuroblastoma [55] and melanoma cells [56], resulting in cell death. By inhibiting MCT1, lactate is not available to aerobic cells, so it induces a switch from lactate-fuelled respiration to glycolysis, accompanied by a retardation of tumor growth in a mouse model of lung carcinoma and in transplanted human colorectal carcinoma [47]. Several MCT inhibitors have been described but none of them is specific, as cyanocinnamate derivatives (e.g. $\alpha$-cyano-4-hydroxycinnamate or $\mathrm{CHC}$ ), bioflavonoids (e.g. phloretin and quercetin), anion transport inhibitors (e.g. niflumic acid and 5-nitro-2-(3-phenylpropylamino) benzoate or NPPB), or stilbenedilsulfonates (e.g. 4,4'-dibenzamidostilbene-2,2'-disulfonate or DIDS) [57]. A recent MCT1-specific inhibitor, AR-C117977, was found to possess immunosuppressive properties that prolongs skin graft and heart allograft survival in mice [58]. MCT1 knockdown suppressed metastatic dissemination of osteosarcoma cells with a mechanism related to NF-kB pathway inhibition [59].

Metformin (N?,N?-dimethylbiguanide) is one of most widely prescribed oral hypoglycemic agent used in type 2 diabetes and also in polycystic ovarian syndrome (PCOS), where insulin resistance is a key factor for metabolic disturbance development. Recently Metformin received increased attention, since its use may reduce cancer risk $[60,61]$ and may improve cancer prognosis, independently of its hypoglycaemic effect [62]. Metformin acts through inhibition of mitochondrial respiration by inhibiting complex I of electron transport chain and hence is an example of mitochondrial metabolic inhibitor blocking oxidative respiration [63], although metformin may also acts decreasing levels of insulin and insulin-related growth factor. This results in increased cellular AMP-to-ATP ratio which, through AMPK activation, promotes GLUT1 expression [64] and PFK-2 phosphorylation stimulating glycolysis [65]. Metforminside effect is represented by lactic acidosis, although this effect is dose-dependent and dichloroacetate (DCA) may be used to treat this metabolic effect. DCA may work as anticancer agent working as inhibitor of PDK [66]. Metformin is also a potent blocker of cell proliferation by inhibiting mTORC1 complex $[67,68]$ and induces cell apoptosis through activating JNK/p38 MAPK pathway [69]. In addition, metformin may upregulate several mRNAs belonging to energy metabolism pathway and downregulates c-Myc, IRS-2 and HIF $1 \alpha$ messanger RNAs, effective in reducing incidence and mortality in breast cancer-bearing mice [70]. Combined treatment with metformin and chemotherapeutic agents has been studied using in vivo models of breast, prostate and lung cancer. One example is the combination of metformin and doxorubicin, that kills both mammary cancer stem cells and non cancer stem cells [71], or the combination of metformin and 2-DG that has a much stronger deleterious effect than either drug in prostate cancer [72]. As an additional point, it was found that metformin inhibits osteosarcoma growth amplifying the effect of cisplatin [73].

\section{CONCLUSIONS}

It is well recognized that tumor microenvironment, due to an altered and not completely organized vascular network together with a reduced intratumoral lymphatic vessels, suffers from ischemic hypoxia which participates to acidosis development. Thus, tumor cells need to adapt their metabolism to regional variation in glucose and oxygen concentration switching from glycolysis to OxPhos, in order to proliferate or expand into surrounding tissues. Thus, metabolic reprogramming renders cancer cells prone to be perturbed by pharmacological agonists or antagonists disclosing new opportunities for therapy. However, the available metabolic agents are very limited, justifying the search for new products targeting metabolic pathway of tumor cells.

\section{ACKNOWLEDGMENTS}

This study was financially supported by grants from Istituto Toscano Tumori, Ente Cassa di Risparmio di Firenze (Progetto Melanoma).

\section{CONFLICT OF INTEREST}

The authors declare that they have no competing interests.

\section{REFERENCES}

1. Greaves M., Maley CC. Clonal evolution in cancer. Nature. 2012; 481: 306-313.

2. Schulze A, Harris AL. How cancer metabolism is tuned for 
proliferation and vulnerable to disruption. Nature. 2012; 491: 364-73.

3. DeBerardinis RJ, Lum JJ, Hatzivassiliou G, Thompson CB. The biology of cancer: metabolic reprogramming fuels cell growth and proliferation. Cell Metab. 2008; 7: 11-20.

4. Kroemer G, Pouyssegur J. Tumor cell metabolism: cancer's Achilles' heel. Cancer Cell. 2008; 13: 472-82.

5. Hanahan D, Weinberg RA. Hallmarks of cancer: the next generation. Cell. 2011; 144: 646-74.

6. Cairns RA, Harris IS, Mak TW. Regulation of cancer cell metabolism. Nat Rev Cancer. 2011; 11: 85-95.

7. Levine AJ, Puzio-Kuter AM. The control of the metabolic switch in cancers by oncogenes and tumor suppressor genes. Science. 2010; 330: 1340-4.

8. Semenza GL. Tumor metabolism: cancer cells give and take lactate. J Clin Invest. 2008; 118: 3835-7.

9. Vander Heiden MG, Cantley LC, Thompson CB. Understanding the Warburg effect: the metabolic requirements of cell proliferation. Science. 2009; 324: 1029-33.

10. Fantin VR, St-Pierre J, Leder P. Attenuation of LDH-A expression uncovers a link between glycolysis, mitochondrial physiology, and tumor maintenance. Cancer Cell. 2006; 9: 425-34.

11. DeBerardinis RJ, Mancuso A, Daikhin E, Nissim I, Yudkoff M, Wehrli S, Thompson CB. Beyond aerobic glycolysis: transformed cells can engage in glutamine metabolism that exceeds the requirement for protein and nucleotide synthesis. Proc Natl Acad Sci U S A. 2007; 104: 19345-50.

12. WARBURG O. On the origin of cancer cells. Science. 1956; 123: 309-14.

13. Gatenby RA, Gillies RJ. Why do cancers have high aerobic glycolysis? Nat Rev Cancer. 2004; 4: 891-9.

14. David CJ, Chen M, Assanah M, Canoll P, Manley JL. HnRNP proteins controlled by c-Myc deregulate pyruvate kinase mRNA splicing in cancer. Nature. 2010,; 463: 364-8.

15. Yeung SJ, Pan J, Lee MH. Roles of p53, MYC and HIF-1 in regulating glycolysis - the seventh hallmark of cancer. Cell Mol Life Sci. 2008; 65: 3981-3999.

16. Shim H, Dolde C, Lewis BC, Wu CS, Dang G, Jungmann RA, Dalla-Favera R, Dang CV. c-Myc transactivation of LDH-A: implications for tumor metabolism and growth. Proc Natl Acad Sci U S A. 1997; 94: 6658-63.

17. Elstrom RL, Bauer DE, Buzzai M, Karnauskas R, Harris MH, Plas DR, Zhuang H, Cinalli RM, Alavi A, Rudin CM, Thompson CB. Akt stimulates aerobic glycolysis in cancer cells. Cancer Res. 2004; 64: 3892-9.

18. Testa JR, Tsichlis PN. AKT signaling in normal and malignant cells. Oncogene. 2005; 24: 7391-3.

19. Christofk HR, Vander Heiden MG, Harris MH, Ramanathan A, Gerszten RE, Wei R, Fleming MD, Schreiber SL, Cantley LC. The M2 splice isoform of pyruvate kinase is important for cancer metabolism and tumour growth.
Nature. 2008; 452: 230-3.

20. Vaupel PW. Blood flow, oxygenation, tissue $\mathrm{pH}$ distribution, and bioenergetic status of tumors. In: Ernst Schering Research Foundation. Lecture 23. Berlin: Information and Standards Medical Scientific Publications; 1994.p13-14.

21. Vaupel P. Is there a critical tissue oxygen tension for bioenergetic status and cellular $\mathrm{pH}$ regulation in solid tumors? Experientia. 1996; 52: 464-468.

22. Gambhir SS. Molecular imaging of cancer with positron emission tomography. Nat Rev Cancer. 2002; 2: 683-93.

23. Jones RG, Thompson CB. Tumor suppressors and cell metabolism: a recipe for cancer growth. Genes Dev. 2009; 23: 537-48.

24. Semenza GL. Targeting HIF-1 for cancer therapy. Nat Rev Cancer. 2003; 3: 721-32.

25. Pouysségur J, Dayan F, Mazure NM. Hypoxia signalling in cancer and approaches to enforce tumour regression. Nature. 2006; 441: 437-43.

26. Denko NC. Hypoxia, HIF1 and glucose metabolism in the solid tumour. Nat Rev Cancer. 2008; 8: 705-13.

27. Polyak K, Weinberg RA. Transitions between epithelial and mesenchymal states: acquisition of malignant and stem cell traits. Nat Rev Cancer. 2009; 9: 265-73.

28. DeBerardinis RJ. Is cancer a disease of abnormal cellular metabolism? New angles on an old idea. Genet Med. 2008; 10: 767-77.

29. Metallo CM, Gameiro PA, Bell EL, Mattaini KR, Yang J, Hiller K, Jewell CM, Johnson ZR, Irvine DJ, Guarente L, Kelleher JK, Vander Heiden MG, Iliopoulos O, Stephanopoulos G. Reductive glutamine metabolism by IDH1 mediates lipogenesis under hypoxia. Nature. 2011; 481: 380-4.

30. Goda N, Ryan HE, Khadivi B, McNulty W, Rickert RC, Johnson RS. Hypoxia-inducible factor 1alpha is essential for cell cycle arrest during hypoxia. Mol Cell Biol 2003, 23:359-69.

31. Bristow RG, Hill RP. Hypoxia and metabolism. Hypoxia, DNA repair and genetic instability. Nat Rev Cancer. 2008; 8: $180-92$.

32. Keith B, Simon MC. Hypoxia-inducible factors, stem cells, and cancer. Cell. 2007; 129: 465-72.

33. Svastová E, Hulíková A, Rafajová M, Zat'ovicová M, Gibadulinová A, Casini A, Cecchi A, Scozzafava A, Supuran CT, Pastorek J, Pastoreková S. Hypoxia activates the capacity of tumor-associated carbonic anhydrase IX to acidify extracellular pH. FEBS Lett. 2004; 577: 439-45.

34. Koukourakis MI, Giatromanolaki A, Harris AL, Sivridis E. Comparison of metabolic pathways between cancer cells and stromal cells in colorectal carcinomas: a metabolic survival role for tumor-associated stroma. Cancer Res. 2006; 66: 632-637.

35. Peppicelli S, Bianchini F, Calorini L. Extracellular acidity, a "reappreciated" trait of tumor environment driving 
malignancy: perspectives in diagnosis and therapy. Cancer Metastasis Rev. 2014; 33: 823-32.

36. Damaghi M, Wojtkowiak JW, Gillies RJ. pH sensing and regulation in cancer. Front Physiol. 2013; 4: 370

37. Parks SK, Chiche J, Pouysségur J. Disrupting proton dynamics and energy metabolism for cancer therapy. Nat Rev Cancer. 2013; 13: 611-23.

38. Peppicelli S, Bianchini F, Torre E, Calorini L. Contribution of acidic melanoma cells undergoing epithelial-tomesenchymal transition to aggressiveness of non-acidic melanoma cells. Clin Exp Metastasis. 2014 [Epub ahead of print].

39. Tang X, Lucas JE, Chen JL, LaMonte G, Wu J, Wang MC, Koumenis C, Chi JT. Functional interaction between responses to lactic acidosis and hypoxia regulates genomic transcriptional outputs. Cancer Res. 2012; 72: 491-502.

40. Mazzio EA, Boukli N, Rivera N, Soliman KF. Pericellular $\mathrm{pH}$ homeostasis is a primary function of the Warburg effect: inversion of metabolic systems to control lactate steady state in tumor cells. Cancer Sci. 2012; 103: 422-32.

41. Burd R, Wachsberger PR, Biaglow JE, Wahl ML, Lee I, Leeper DB. Absence of Crabtree effect in human melanoma cells adapted to growth at low $\mathrm{pH}$ : reversal by respiratory inhibitors. Cancer Res. 2001; 61: 5630-5.

42. Kahn BB, Alquier T, Carling D, Hardie DG. AMP-activated protein kinase: ancient energy gauge provides clues to modern understanding of metabolism. Cell Metab. 2005; 1 : $15-25$.

43. Lamonte G, Tang X, Chen JL, Wu J, Ding CK, Keenan MM, Sangokoya C, Kung HN, Ilkayeva O, Boros LG, Newgard CB, Chi JT. Acidosis induces reprogramming of cellular metabolism to mitigate oxidative stress. Cancer Metab. 2013; 1: 23.

44. Peppicelli S, Bianchini F, Contena C, Tombaccini D, Calorini L. Acidic $\mathrm{pH}$ via NF- $\mathrm{BB}$ favours VEGF-C expression in human melanoma cells. Clin Exp Metastasis. 2013; 30: 957-67.

45. Fiaschi T, Marini A, Giannoni E, Taddei ML, Gandellini P, De Donatis A, Lanciotti M, Serni S, Cirri P, Chiarugi P. Reciprocal metabolic reprogramming through lactate shuttle coordinately influences tumor-stroma interplay. Cancer Res. 2012; 72: 5130-40.

46. Whitaker-Menezes D, Martinez-Outschoorn UE, Lin Z, Ertel A, Flomenberg N, Witkiewicz AK, Birbe RC, Howell A, Pavlides S, Gandara R, Pestell RG, Sotgia F, Philp NJ, Lisanti MP. Evidence for a stromal-epithelial "lactate shuttle" in human tumors: MCT4 is a marker of oxidative stress in cancer-associated fibroblasts. Cell Cycle. 2011; 10: 1772-83.

47. Sonveaux P, Végran F, Schroeder T, Wergin MC, Verrax J, Rabbani ZN, De Saedeleer CJ, Kennedy KM, Diepart C, Jordan BF, Kelley MJ, Gallez B, Wahl ML, Feron O, Dewhirst MW. Targeting lactate-fueled respiration selectively kills hypoxic tumor cells in mice. J Clin Invest.
2008; 118: 3930-42.

48. Corbet C, Draoui N, Polet F, Pinto A, Drozak X, Riant O, Feron O. The SIRT1/HIF2 $\alpha$ Axis Drives Reductive Glutamine Metabolism under Chronic Acidosis and Alters Tumor Response to Therapy. Cancer Res. 2014; 74: 550719.

49. Stüwe L, Müller M, Fabian A, Waning J, Mally S, Noël J, Schwab A, Stock C. pH dependence of melanoma cell migration: protons extruded by NHE1 dominate protons of the bulk solution. J Physiol. 2007; 585: 351-60.

50. LeBleu VS, O'Connell JT, Gonzalez Herrera KN, Wikman H, Pantel K, Haigis MC, de Carvalho FM, Damascena A, Domingos Chinen LT, Rocha RM, Asara JM, Kalluri R. PGC- $1 \alpha$ mediates mitochondrial biogenesis and oxidative phosphorylation in cancer cells to promote metastasis. Nat Cell Biol. 2014; 16: 992-1003.

51. Maher JC, Krishan A, Lampidis T. Greater cell cycle inhibition and cytotoxicity induced by 2-deoxy-D-glucose in tumor cells treated under hypoxic vs aerobic condition. Cancer Chemother Pharmacol. 2004; 53: 116-22.

52. Maschek G, Savaraj N, Priebe W, Braunschweiger P, Hamilton K, Tidmarsh GF, De Young LR, Lampidis TJ. 2-Deoxy-D-glucose increases the efficacy of Adriamycin and paclitaxel in human osteosarcoma and non-small cell lung cancers in vivo. Cancer Res. 2004; 64: 31-4.

53. Geschwind JF, Ko YH, Torbenson MS, Magee C, Pedersen PL. Novel therapy for liver cancer: direct intraarterial injection of a potent inhibitor of ATP production. Cancer Res. 2002; 62: 3909-13.

54. Xu RH, Pelicano H, Zhou Y, Carew JS, Feng L, Bhalla $\mathrm{KN}$, Keating MJ, Huang P. Inhibition of glycolysis in cancer cells: a novel strategy to overcome drug resistance associated with mitochondrial respiratory defect and hypoxia. Cancer Res. 2005; 65: 613-21.

55. Fang J, Quinones QJ, Holman TL, Morowitz MJ, Wang Q, Zhao H, Sivo F, Maris JM, Wahl ML. The H+-linked monocarboxylate transporter (MCT1/SLC16A1): a potential therapeutic target for high-risk neuroblastoma. Mol Pharmacol. 2006; 70: 2108-15.

56. Wahl ML, Owen JA, Burd R, Herlands RA, Nogami SS, Rodeck U, Berd D, Leeper DB,Owen CS. Regulation of intracellular $\mathrm{pH}$ in human melanoma: potential therapeutic implications. Mol. Cancer Ther. 2002; 1: 617- 628.

57. Kennedy KM, Dewhirst MW. Tumor metabolism of lactate: the influence and therapeutic potential for MCT and CD147 regulation. Future Oncol. 2010; 6: 127-48.

58. Bueno V, Binet I, Steger U, Bundick R, Ferguson D, Murray C, Donald D, Wood K. The specific monocarboxylate transporter (MCT1) inhibitor, AR-C117977, a novel immunosuppressant, prolongs allograft survival in the mouse. Transplantation. 2007; 84: 1204-7.

59. Zhao Z, Wu MS, Zou C, Tang Q, Lu J, Liu D, Wu Y, Yin J, Xie X, Shen J, Kang T, Wang J. Downregulation of MCT1 inhibits tumor growth, metastasis and enhances 
chemotherapeutic efficacy in osteosarcoma through regulation of the NF- $\kappa$ B pathway. Cancer Lett. 2014; 342: 150-8.

60. Evans JM, Donnelly LA, Emslie-Smith AM, Alessi DR, Morris AD. Metformin and reduced risk of cancer in diabetic patients. BMJ. 2005; 330:1304-5.

61. Lee MS, Hsu CC, Wahlqvist ML, Tsai HN, Chang YH, Huang YC. Type 2 diabetes increases and metformin reduces total, colorectal, liver and pancreatic cancer incidences in Taiwanese: a representative population prospective cohort study of 800,000 individuals. BMC Cancer. 2011; 11: 20

62. Kourelis TV, Siegel RD. Metformin and cancer: new applications for an old drug. Med Oncol. 2012; 29: 131427.

63. El-Mir MY, Nogueira V, Fontaine E, Avéret N, Rigoulet M, Leverve X. Dimethylbiguanide inhibits cell respiration via an indirect effect targeted on the respiratory chain complex I. J Biol Chem. 2000; 275: 223-228.

64. Fryer LG, Foufelle F, Barnes K, Baldwin SA, Woods A, Carling D. Characterization of the role of the AMPactivated protein kinase in the stimulation of glucose transport in skeletal muscle cells. Biochem J. 2002; 363: 167174

65. Marsin AS, Bertrand L, Rider MH, Deprez J, Beauloye C, Vincent MF, Van den Berghe G, Carling D, Hue L. Phosphorylation and activation of heart PFK-2 by AMPK has a role in the stimulation of glycolysis during ischaemia. Curr Biol. 2000; 10: 1247-1255.

66. Michelakis ED, Webster L, Mackey JR. Dichloroacetate (DCA) as a potential metabolic-targeting therapy for cancer. Br J Cancer. 2008; 99: 989-94.
67. Zakikhani M, Dowling R, Fantus IG, Sonenberg N, Pollak M. Metformin Is an AMP Kinase-Dependent Growth Inhibitor for Breast Cancer Cells. Cancer Res. 2006; 66: 10269-73.

68. Cantrell LA, Zhou C, Mendivil A, Malloy KM, Gehrig PA, Bae-Jump VL. Metformin is a potent inhibitor of endometrial cancer cell proliferation-implications for a novel treatment strategy. Gynecologic Oncology. 2010; 116: 92-8.

69. Xiong Y, Lu QJ, Zhao J, Wu GY. Metformin inhibits growth of hepatocellular carcinoma cells by inducing apoptosis via mitochondrion-mediated pathway. Asian Pac J Cancer Prev. 2012; 13: 3275-9.

70. Blandino G, Valerio M, Cioce M, Mori F, Casadei L, Pulito C, Sacconi A, Biagioni F, Cortese G, Galanti S, Manetti C, Citro G, Muti P, Strano S. Metformin elicits anticancer effects through the sequential modulation of DICER and c-MYC. Nat Commun. 2012; 3: 865.

71. Hirsch HA, Iliopoulos D, Tsichlis PN, Struhl K. Metformin selectively targets cancer stem cells, and acts together with chemotherapy to block tumor growth and prolong remission. Cancer Res. 2009; 69: 7507-7511.

72. Ben Sahra I, Laurent K, Giuliano S, Larbret F, Ponzio G, Gounon P, Le Marchand-Brustel Y, Giorgetti-Peraldi S, Cormont M, Bertolotto C, Deckert M, Auberger P, Tanti JF, Bost F. Targeting cancer cell metabolism: the combination of metformin and 2-deoxyglucose induces p53-dependent apoptosis in prostate cancer cells. Cancer Res. 2010; 70: 2465-75.

73. Quattrini I, Conti A, Pazzaglia L, Novello C, Ferrari S, Picci $\mathrm{P}$, Benassi MS. Metformin inhibits growth and sensitizes osteosarcoma cell lines to cisplatin through cell cycle modulation. Oncol Rep. 2014; 31: 370-5. 